
when a physician could be called for a would be especially useful with home te undesirable interactins of prescribed and over-the-counter drugs and other substances.

Implications of

echnological Innovation

The issues surrounding the extension of

\begin{abstract}
DEPARTMENT OF COMMUNICATIONS
\end{abstract}

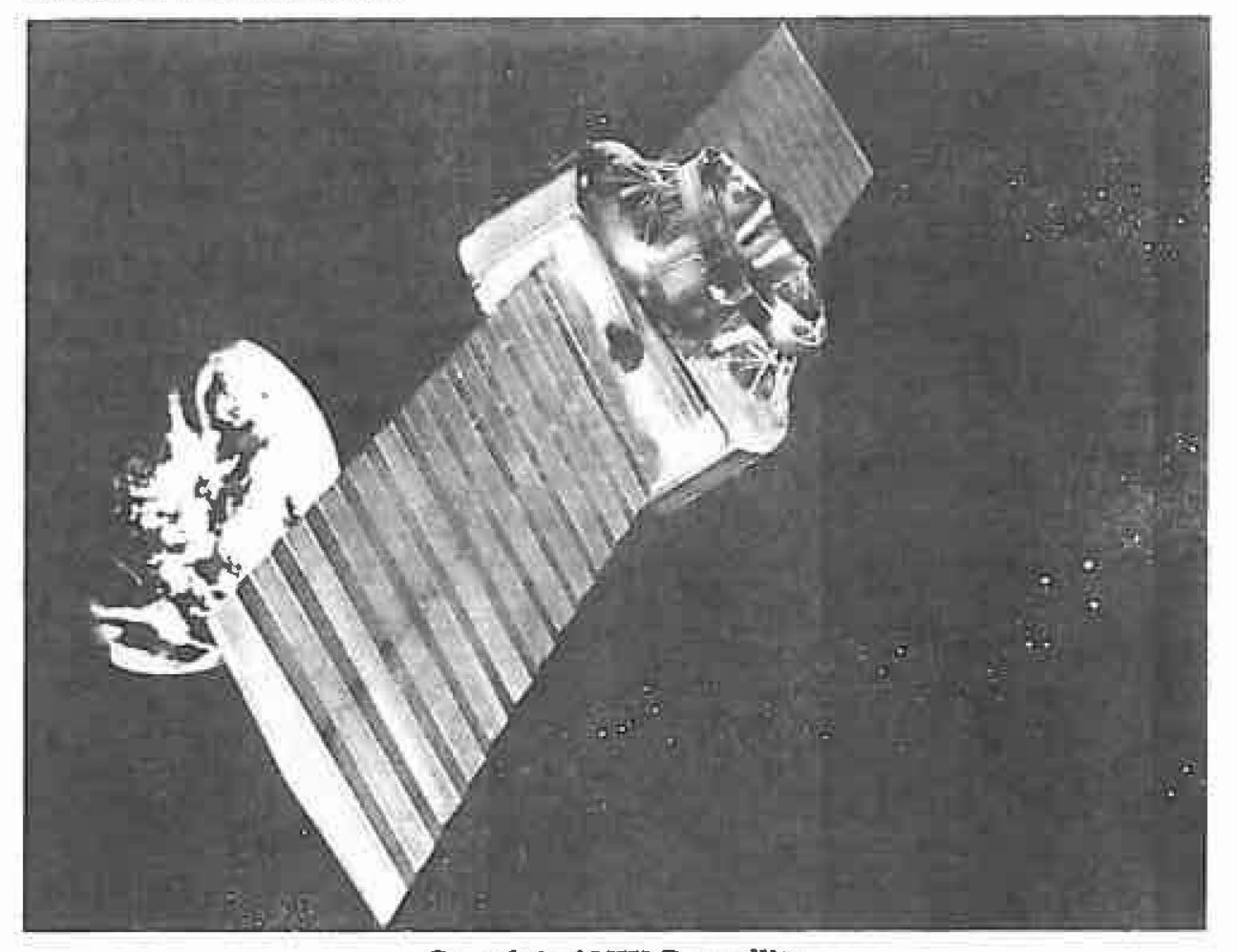

Canada's ANIK B satellite

grounds, ethnic identity and heallh status,
Fourth, health education programs shoul ore than information needs they should also be designed to include
educational components that could have an impact on attitudes and behaviours. What kinds of programs could we pro-
vide for health education? I think the vide for health education?
possibilities are endless and think the are many creative minds out there that could provide quality applications. To begin
vith, however, we could have numerou with, however, we could have numerous
self-evaluation applications; e.g., comsell-evaluation applicationsi e.g.g. com
puterized dietary analysis with immediate feedback to the user, lifies-style evaluation.
with assessment of health risk factors and eedback re: impact on life expectancy; or stress analysis. Other possibilitities migh
include a first aid program which could utilize the branching capabililites of the computer to lead the user quickly through
decision making to delermine rationally will be due in part from the substitutio ple can be reached with a more consisten message using the new technologies -
hundreds or thousands at one time as conminals. Another useful program migh trasted with the ten to twelve per day who health educators at present. Considering interest rates, the high start-up costs may delay the utilization of the new tech. nologies, however. The use of such medi por health education would require strong ficult for politicians to justify the massive costs at a time when there are many othe

pressing demands.
Finally, to realize potential cost reduc tions, large numbers of instructiona
devices must be utilized and curricula will have to be centrally produced. Due to the economics of sale, specialized pro-
grams are very expensive while those grams are very expensive while those
which have a broad application are much Erkel (1979) found that unless healt lifestyles and needs, they will not be im plemented. Taking this into consideration then, the centralization of production,
while it would decrease costs, could lead while it would decrease costs, could lead
to totally ineffective programs. Something to totally ineffective programs. Something
produced for the Maritimes or a Toronto audience might be culturally and ethnically inappropriate for a target audience in
northern Manitoba since it would depic an environment greatly divergent fro be concerned about the appropriatenes of educational level.

Considering the diversity of needs in least regional needs considered. Debbie Bulger (1982) and her colleagues in making a videotape for families of their patient population at the University of Te the patient population. Skin tones in the graphics were ambiguous so that white families would see a white mother and baby and black families would see a black mother and baby. Professionals and pa-
jents were of both races and all had southern accents. They found that thes details made the viewers more comfoThis experience illustrates the poin This experience illustrates the point
made by Zimbardo (1977) - that the likelihood that a receiver will accept the conclusions advocated in a given message
is in part a function of the receiver's is in part a function of the receiver's
perception of the source's credibility perception of the source's credibility
which, in turn, is in part dependent on source-receiver dependability. Similar conclusions have been made from work
done by communications theorists at Yale done by communications theorists at Yale
University. Psychological factors are im. portant in any communication but especially so when technology is used. It
is most important to pay attention to ith local context and provide hurnan suppor systems especially in remole areas. It is
essential that we balance the need for economy of scale with the needs of various cultural or regional groups.
$\mathrm{A}$ further consequence of the new in-

VOLUME 12, NUMBER 3, 1983 decrease local control over content.

probably do far more to curb individual hat resources can be used to in dividualize while human beings can be perience and learning envire learning erience and learning environment. is as a guide, catalyst, learning helper and motivator as well as
expert learner. The content of expert learner. The content of
knowledge will be contained in resources such as books, cmputers, videotapes, audiotapes, television and other people. Know-
ledge itself is as much the process ledge itself is as much the process
or skill of acquiring it as it is the or skill of acquiring it as it is the
content and so any human assistance must be well versed in process as well." (15:369) As mentioned throughout this paper,
there must be skilled people, facilities for

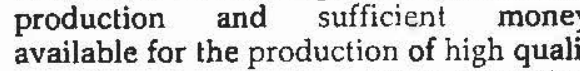
ty software in order to make an education
program successful. When introducin program successful. When introducing
any innovation, it is also important to conany innovation, it is also important
sider the attitudes and values of the targe

population in reference to the change. In-
dividuals need time and assistance to adForsythe and Hart (1980) feel that what seems to be overlooked in the argumen

\section{How it Works: Guided Wave Optics}

\begin{tabular}{ll} 
CROSS & INPUT OUTPUT \\
SECTION & LIGHT PATH PULSE PULSE \\
\hline
\end{tabular}

Figure 1.

Single-Mode

Stepped

Figure 2.

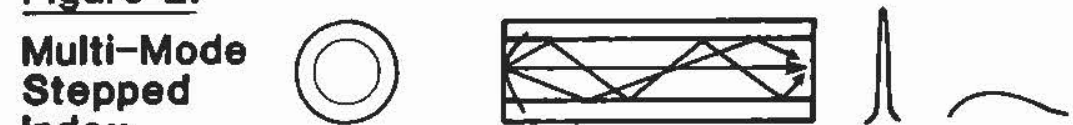

Index

Figure 3.

Multi-Mode

Graded
Index

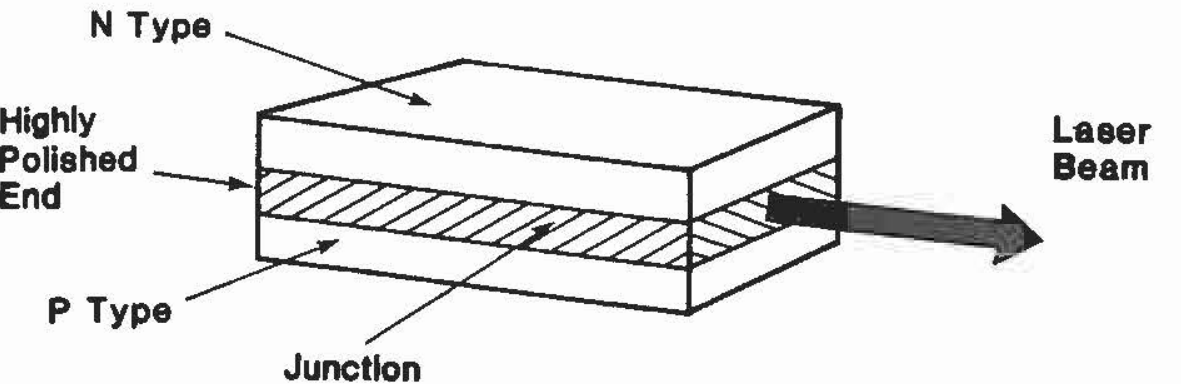

Figure 4. Semiconductor Injectlon Laser DEMODULATOR cladding
Just. In the case of this health education he focus from illness to wellness, and the responsibility for wellness from the
government or the medical profession to

Conclusions

The current economic situation
together with swiftly rising health care costs are putting great pressure on the health within our resource base? Another pressure is public expectations. There has been a continuing growth in public
awareness in the health care fields, coming in part from the generally increasin
levels of education. A public which is
knowledgeable both demands and expects more. The existence of a universal medicare system contributes to these ex requires health care, not only is it
available to all but also accessible to all. If
is evident that it is more usual for the aris evident that it is more usual for the ar
ticulate middle class to take maximum advantage. A caring sociely may have as its er understanding and use of commmunity
Continued on page 28

An optical fibre is a cylindical glass core of uniform refraction surrounded by a concentric layer (the cladding) which
has a lower index of refraction. Light enters one end and as it disperses along by the cladding. The core diameter of
single-(monol mode fibres (figure 1 ) is
$7-10$ millionths of a meter (micrometers). 7-10 millionths of a meter (micrometers)
Multi-mode graded index fibres (figure 3 ) lines because they are easier to join (the cores are larger than single-mode fibres)
and light dispersion is not as bad as with stepped-index fibres (figure 2). Light signals are generated in digital code by semiconductor injection lasers (figure 4]. An electron moves from the to the positive (P-type) material as an electrical current is applied. As the electron
crosses the junction energy is lost which is emitted as light.

Technological advances soon will make in possible to use single-mode fibres. New
installation equipment will allow technicians to align the smaller cores in the
field. Newer lasers capable of generating light pulses in picoseconds (trillionths of ingle-mode fibres. These fibres can carn over 100,000 telephone conversations simultaneously, and television, videotex
or other broadband data transmissions at 9600 bits broadband 